\title{
Risk, uncertainty, and heuristics ${ }^{\Uparrow}$
}

\author{
Shabnam Mousavi ${ }^{\mathrm{a}, \mathrm{b}, *}$, Gerd Gigerenzer ${ }^{\mathrm{b}}$ \\ a Johns Hopkins Carey Business School, 1625 Massachusetts Ave, NW, Washington, DC 20036, USA \\ b Center for Adaptive Behavior and Cognition, Max Planck Institute for Human Development, Lentzeallee 94, 14195 Berlin, Germany
}

\section{A R T I C L E I N F O}

\section{Article history:}

Received 1 September 2013

Received in revised form 1 December 2013

Accepted 1 January 2014

Available online 19 March 2014

\section{Keywords:}

Uncertainty

Fast-and-frugal heuristics

Business decision-making

Complexity

\begin{abstract}
A B S T R A C T
Nearly a century ago, Frank Knight famously distinguished between risk and uncertainty with respect to the nature of decisions made in a business enterprise. He associated generating economic profit with making entrepreneurial decisions in the face of fundamental uncertainties. This uncertainty is complex because it cannot be reliably hedged unless it is reducible to risk. In making sense of uncertainty, the mathematics of probability that is used for risk calculations may lose relevance. Fast-and-frugal heuristics, on the other hand, provide robust strategies that can perform well under uncertainty. The present paper describes the structure and nature of such heuristics and provides conditions under which each class of heuristics performs successfully. Dealing with uncertainty requires knowledge but not necessarily an exhaustive use of information. In many business situations, effective heuristic decision-making deliberately ignores information and hence uses fewer resources. In an uncertain world, less often proves to be more.
\end{abstract}

(c) 2014 Elsevier Inc. All rights reserved.
If we are to understand the workings of the economic system we must examine the meaning and significance of uncertainty; and to this end some inquiry into the nature and function of knowledge itself is necessary. (Frank Knight, 1921, p. 199)

\section{Introduction}

At the Federal Reserve's annual policy conference in August 2012, Bank of England's executive director for financial stability, Andrew Haldane, proclaimed: "Modern finance is complex, perhaps too complex. Regulation of modern finance is complex, almost certainly too complex. That configuration spells trouble. As you do not fight fire with fire, you do not fight complexity with complexity. Because complexity generates uncertainty, not risk, it requires a regulatory

\footnotetext{
it The title of this paper was inspired by Frank Knight's Risk, Uncertainty, and Profit, a work that underlies a major part of the arguments presented here. The authors are grateful to Florian Artinger, Nathan Berg, Jerry Busby, Mario Fific, Mirta Galesic, Kevin Gluck, Hans Haller, Edi Karni, Christian Kim, Sharon Kim, Konstantinos Katsikopoulos, Amit Kothiyal, Adam Litwin, Julian Marewski, Henrik Olsson, Phil Phan, Markus Raab, Florian von Wangenheim, Arch Woodside, and Meng Zhu for providing valuable input in developing this volume, and for pointing us to related literature for this article. Comments and discussions following presentation of this paper at the Department of Economics at Virginia Tech were also extremely helpful. The usual disclaimer applies.

* Corresponding author at: Johns Hopkins Carey Business School, USA, and Max Planck Institute for Human Development Berlin, Germany.

E-mail addresses: shabnam@jhu.edu, mousavi@mpib-berlin.mpg.de (S. Mousavi), gigerenzer@mpib-berlin.mpg.de (G. Gigerenzer).
}

response grounded in simplicity, not complexity" (Haldane, 2012). Financial media praised his proposed reform of financial regulations through the use of simple heuristics that can deal with complexity, and The Wall Street Journal named Haldane's talk "Speech of the Year." The exploration of simple rules, which can outperform complex algorithms in real world situations-namely, the study of fastand-frugal heuristics-is the content of a research program that investigates ecological rationality. The term ecological rationality refers to functional matches between cognition and environment, and thus generates insight for engineering environments that are most conducive to achieving certain tasks (Gigerenzer, Hertwig, \& Pachur, 2011; Todd, Gigerenzer, \& the ABC Research group, 2012). A heuristic is ecologically rational to the degree it matches the structure of the environment. Haldane's talk, "The dog and the Frisbee," was named after one of these simple rules - the gaze heuristic - which both dogs and baseball players rely on to solve a difficult problem, namely how to catch an object which is flying against a noisy background (Gigerenzer, 2007).

If dogs or people could reliably estimate all factors that affect the trajectory of a ball or Frisbee, including spin and wind, no heuristics would be needed. Similarly, in most real-world tasks such as reducing the chances of another financial crisis or increasing the financial stability in the economic system environment, these factors are hard to estimate, and calculations can provide illusory certainty (Shefrin, 2013). The study of ecological rationality characterizes both heuristics and the environmental structures in which a given heuristic can be successful for a given task. Heuristic strategies are structurally simple and reliable when optimization algorithms lose feasibility, which makes them 
potentially the best strategies available for particular problems; in cognitive sciences this coincides with normativity.

According to the ecological rationality framework, the knowledge of how people should make decisions cannot be studied without considering how people are able to make decisions. This view of knowledge, in turn, rejects the segregation of psychology from disciplines such as logic, statistics, and philosophy. In sum, the study of simple heuristics has generated precisely the type of knowledge that allows for normative statements to be made based on descriptive assessments of the human adaptive toolbox, that is, the heuristics people have in their repertoire. Gigerenzer and Sturm (2012) provide a detailed argument for the normativity and naturalization of heuristics, illustrated by cases where norms can be derived from empirical studies of human reasoning.

Heuristics are tools that are developed by direct learning or over the course of evolution. This paper summarizes findings from the study of heuristics in different contexts. When comparing uncertainty of realworld situations with the architecture of calculated risk, it becomes clear that most daily business decision-making situations are of the former type. Moreover, a complex uncertain problem often calls for a simple robust solution. Heuristic strategies are simple rules of thumb that solve complex uncertain situations precisely because of their simplicity, not despite it (Gigerenzer, Todd, \& the ABC Research Group, 1999). More calculation, time, and information are not always better. Less can be more.

In the traditional literature on risk management, decision-making situations are classified into three categories: certainty, risk, and uncertainty. Under certainty, each action is known to lead to a certain outcome. Under risk, all outcomes as well as the probabilities of each outcome are known. Under uncertainty, outcomes are still known but not necessarily all their probabilities. Managerial perspectives on risk taking are thus customarily studied with respect to this categorization (Shapira, 1994). While acknowledging the abovementioned situations, we go beyond them to include situations of fundamental uncertainty, in which some of the alternatives and outcomes, in addition to probabilities, can be unknown. The term uncertainty, here, always means fundamental uncertainty. Many scholars have tried to reduce uncertainty to risk. For instance, Bewley (2002) develops a formalized interpretation of Knightian uncertainty, wherein he treated unknown outcomes by assigning to them an initial probability of zero that can consequently take on non-zero values in the process of decision-making. However, not all problems can be best approached by using the tool of probability theory only. An alternative introduced here is a toolbox of fast and frugal heuristics for decision-making under uncertainty.

\section{Decisions under uncertainty are not the same as decisions under risk}

Do we live in a world of risk? At the roulette table, yes; in the world of business, rarely. Observe, however, that most of decision theory is based on a risk characterization of the uncertain world. But can riskbased rules successfully apply to a world of uncertainty? It depends. The structural difference between risk and uncertainty calls for rules of dealing with uncertainty that are not compatible with risk calculations unless uncertainty can be reliably reduced to a form of risk. Unique situations, uninsurable risk, and lack of properties that satisfy the mathematics of probabilities are all cases in point. In a world of uncertainty, heuristics are indispensable tools, not second-best solutions.

Frank Knight famously made a consequential distinction between risk and uncertainty in relation to the process of profit generation in the markets. In one of the most interesting reads in economics to date, Risk, Uncertainty, and Profit (19r21), he first established that perfect competition co-exists with insurable risk. Notably, he argued that the limitations of perfect competition are embedded in the true uncertainty of situation rather than in the imperfection of knowledge. For Knight, generation of economic profit takes place under fundamental or true uncertainty. Situations of uncertainty are not limited to entrepreneurial cases. In fact, the presence of uncertainty is paramount in a wide range of choice situations in real life. Each of these uncertain situations can be too unique to lend any useful data to statistical analysis and hence preclude not only explicit attainment of even near-perfect knowledge but also measurable probability. Knight provided an illustration (p. 223):

Suppose we are allowed to look into the urn containing a large number of black and red balls before making a wager, but are not allowed to count the balls: this would give rise to an estimate of probability in the correct sense; it is something very different from either the mere consciousness or ignorance on which we act if we know only that there are balls of both colors without any knowledge or opinion as to the numbers or the exact knowledge of real probability attained by an accurate counting of the balls. In the second place, we must admit that the actual basis of action in a large proportion of real cases is an estimate. Neither of these interpretations, however, justifies identifying probability with an estimate. [...] [T] he exact science of inference has little place in forming the opinions upon which decisions of conduct are based, and that this is true whether the implicit logic of the case is prediction on the ground of exhaustive analysis or a probability judgment, a priori or statistical. We act upon estimates rather than inferences, upon "judgment" or "intuition", not reasoning, for the most part.

Notice that these statements were made prior to the modern formalization of decision theory. A reading of Knight's insights in the postSavage era goes like this: Where perfect knowledge and measurable probabilities are the pillars of profit maximization in the competitive market and of expected utility maximization for rational individuals, the same methods lose relevance to a good deal of real-world problems on a different scale.

Looked at from the familiar decision theory framework, what Knight provided is a typology of the ways in which the unknown feature of a situation can be formally characterized and assessed. The first type of assessment is a priori probability, which corresponds to propensities, that is, probabilities known by the design of a die or slot machine, not by observation (Daston, 1988). The second type of assessment is based on collecting empirical and experimental evidence/data from repeated observations in the presence of homogeneity towards establishing what Knight called statistical probability. These two constitute types of measurable risk. On the other hand, Knight observes that "the actual basis of action in a large proportion of real cases is an estimate." (Ibid., p. 223), which is the type of probability of interest to "the student of business." For each type of assessment, the process of information and formation of actionable knowledge can be understood as follows. Probability judgment for the a priori (designed) type is deductive, and for the statistical type inductive, whereas decisions of conduct are based on forming an opinion of a Knightian estimate. We argue that actions in situations under uncertainty are for the most part based on heuristics not on statistical reasoning.

Table 1 connects Knight's typology with the study of heuristics. For type-1 risk (Knightian a priori probability), a probability distribution is known for the limited known space of outcomes, and the information is used to form a deductive knowledge of the situation. The best action simply requires an optimization, or maximization of utility. Type-2 risk (Knightian statistical probability) deals with situations of inductive reasoning. Here, samples and observations have to be collected and aggregated to infer the properties of the true probability distributions. These statistical processes are subject to the trade-off between accuracy and effort. In contrast, decision making under uncertainty refers to situations in which the probabilities cannot be reliably estimated (what Knight called "estimates" or "intuition") or where the set of alternatives and their consequences are not known in the first place (what we refer to as uncertainty). In this situation, probability theory and statistics can no longer find the best solution and other inductive tools are needed, such as heuristics. These heuristics are not subject to the accuracyeffort trade-off - their simplicity is the reason they perform well, by properly matching the heuristic strategy with the environment. Finding the optimal course of action can become infeasible in novel and unique 
Table 1

Decisions under risk vs. uncertainty.

\begin{tabular}{|c|c|c|c|c|}
\hline $\begin{array}{l}\text { Nature of } \\
\text { unknown }\end{array}$ & Knightian probability & Decision process & Method & Generated knowledge \\
\hline Risk & A priori (design; propensity) & Deductive & $\begin{array}{l}\text { Use probability theory to model the underlying } \\
\text { structure; optimization }\end{array}$ & $\begin{array}{l}\text { Deterministic knowledge (as in lotteries); } \\
\text { e.g., objective odds }\end{array}$ \\
\hline Risk & $\begin{array}{l}\text { Statistical (frequencies in the } \\
\text { long run) }\end{array}$ & Inductive (statistical inference) & Use statistical inference; optimization & $\begin{array}{l}\text { Stochastic knowledge; e.g., estimates of } \\
\text { correlations }\end{array}$ \\
\hline Uncertainty & $\begin{array}{l}\text { Estimate; conduct based on } \\
\text { opinion; not fully reasoned }\end{array}$ & Heuristic & $\begin{array}{l}\text { Select a heuristic that is ecologically rational for a } \\
\text { task; exploratory data analysis }\end{array}$ & $\begin{array}{l}\text { Satisficing solutions when optimizing is not } \\
\text { feasible; intuition (as in entrepreneurship) }\end{array}$ \\
\hline
\end{tabular}

situations under uncertainty. In these cases, a Knightian estimate is produced and used for decision-making, which characterizes the last form of Knightian typology. Note that the Knightian "estimate" is to be distinguished from the modern meaning of estimation processes as in probability theory. Unlike these, Knightian estimated probabilities are intuited. Although Knightian estimate might appear similar to probabilities of type-2 risk, it differs in not being reliably measurable.

As mentioned before, uncertainty reaches beyond the Knightian emphasis on estimates of probability. In many business situations, one cannot know the set of alternatives or foresee all outcomes in the first place. As a consequence, expert decisions under uncertainty do not rely on estimating probabilities alone but also on search rules, aspiration levels, lexicographic rules, and other heuristic principles (Gigerenzer et al., 2011). A heuristic can be used unconsciously, fitting Knight's use of the term intuition. Yet every heuristic can also be used consciously and in a reasoned way, as investment heuristics are (see Table 1). If intuitions are based on simple heuristics, then identifying the latter provides insight into the intuitive decisions of managers and institutions. Equally important, this insight can be used for the intuitive design of environments, which enhance performance by triggering successful heuristic strategies.

As Bernstein (1996) observes, "Knight's emphasis on uncertainty decoupled him from dominant economic theory of the time, which emphasized decision-making under conditions of perfect certainty or under established laws of probability-an emphasis that lingers on in certain areas of economic theory today." (Ibid, pp. 219-220; emphasis added) Notably, Knight's typology of probability in relation to risk and uncertainty predates formal decision theory known and studied post Savage (1954). A closer look at Savage's framework is in order to more clearly position this distinction. Savage fully embraces von NeumannMorgenstern expected utility theory, which sets out "Bernoullian utility hypothesis as a consequence of well-accepted maxims of behavior." (Ibid, p. 64) Savage's work, in his own account, draws extensively on von Neumann and Morgenstern (1944) book Theory of Games and Economic Behavior. Von Neumann and Morgenstern proclaim their theoretical approach to rely on "multiple stable standards of behavior." Notably, in interpretation of the utility theory, Savage surpasses them in conviction: "One idea now held by me that I think von Neumann and Morgenstern do not explicitly support, and that so far as I know they might not wish to have attributed to them, is the normative interpretation of the theory" (emphasis added; Savage, 1954, p. 97). This normative interpretation of subjective expected utility gained significant ground afterwards and is today considered mainstream economics. Diverging from this position, we argue in the next section that fast-andfrugal heuristics have empirically based normative implications in addition to descriptive features, especially in situations of uncertainty.

The cost-benefit analysis of economic action goes as follows: Specify the risk involved in the situation, measure it, and price it according to the no-arbitrage or efficient market outcome. Potential profit is generated proportional to the amount of risk undertaken in the markets. In terms of the typology and associations listed in Table 1, under (irreducible) uncertainty, the mathematics of probability is replaced by intuition or gut feelings. Whereas it was not clear at the time of Knight how these intuitions work, the study of fast-and-frugal heuristics has since provided an answer (Gigerenzer, 2007). The main argument here in accordance with Knight is that heuristics are the basis on which humans have made most decisions and survived through time. Empirical evidence from longitudinal studies of the process of executive decisionmaking confirms this assertion. Graham, Harvey, and Puri (2012) report that "almost half of the managers (subscribers to Chief Executive magazine, CFO magazine, CFO Asia, and CFO Europe) consider their gut feel as an important or very important factor in making capital allocation decisions." Fig. 1 depicts the percentage of American CEOs who identified the factors on the vertical axis as important in the process of capital allocation. Capital allocation is the process through which financial resources are allocated to projects - a major and frequent decision in firms. Not surprisingly, the net present value (NPV) method, that is, calculating the sum of discounted future cash flows, which is taught in MBA programs as the best method of valuations, was cited as the most important factor. At the same time, gut feel was declared an important factor by half of the participants. Given that managers are generally reluctant to admit the role of unverifiable factors in their decisions (especially for fear of lacking justification for a decision in the event of failure), this rate of $50 \%$ probably underestimates the true rate. This finding in the area of corporate decision-making concurs with Gigerenzer $(2007,2014)$ focus on the role of unconscious intelligence or gut feelings in successful decision-making. Gigerenzer argues that intuitions can be understood as simple heuristics.

\section{Simple heuristics}

A heuristic is a strategy for making decisions, consciously or unconsciously. The unconscious use of a heuristic is called an intuition (Gigerenzer, 2007), that is, when one senses what to do without being able to explain why. The ecological rationality of a heuristic reflects its degree of adaptation to the structure of an environment. This environment could be a personal choice situation, a business problem, a managerial judgment, or a market condition. A heuristic is not simply a short cut that avoids extra effort at the expense of reduced accuracy. It is a strategy that effectively matches the structure of information in the environment, and in doing so can be ecologically rational. The effectiveness of this ecological match has nothing to do with mimicking the structure of environment in terms of its complexity. Heuristic strategies in fact ignore some of the complexity of the environment (such as available information for estimating correlations from a sample) in order to reduce both the estimation error and effort.

Contrary to a common misunderstanding (e.g. Kahneman \& Frederick, 2002; Shah \& Oppenheimer, 2008), the accuracy-effort trade-off is neither the essence of a heuristic nor does it apply to decisions under uncertainty. The study of fast-and-frugal heuristics has shown that less effort can lead to more accurate judgments. Heuristic strategies use learned and evolved core capacities such as memory and recall. This is why they are fast. An example is the recognition heuristic, which exploits partial knowledge. In Goldstein and Gigerenzer's (2002) experiment, German and U.S. students were asked to make a judgment about the relative size of cities. When asked which of two U.S. cities was larger, Detroit or Milwaukee, German students chose the correct answer 90\% of the time, whereas U.S. students answered $60 \%$ correctly. The German students' limited knowledge about U.S. cities led to the successful use of recognition heuristic, which assigns a higher value to the recognized 


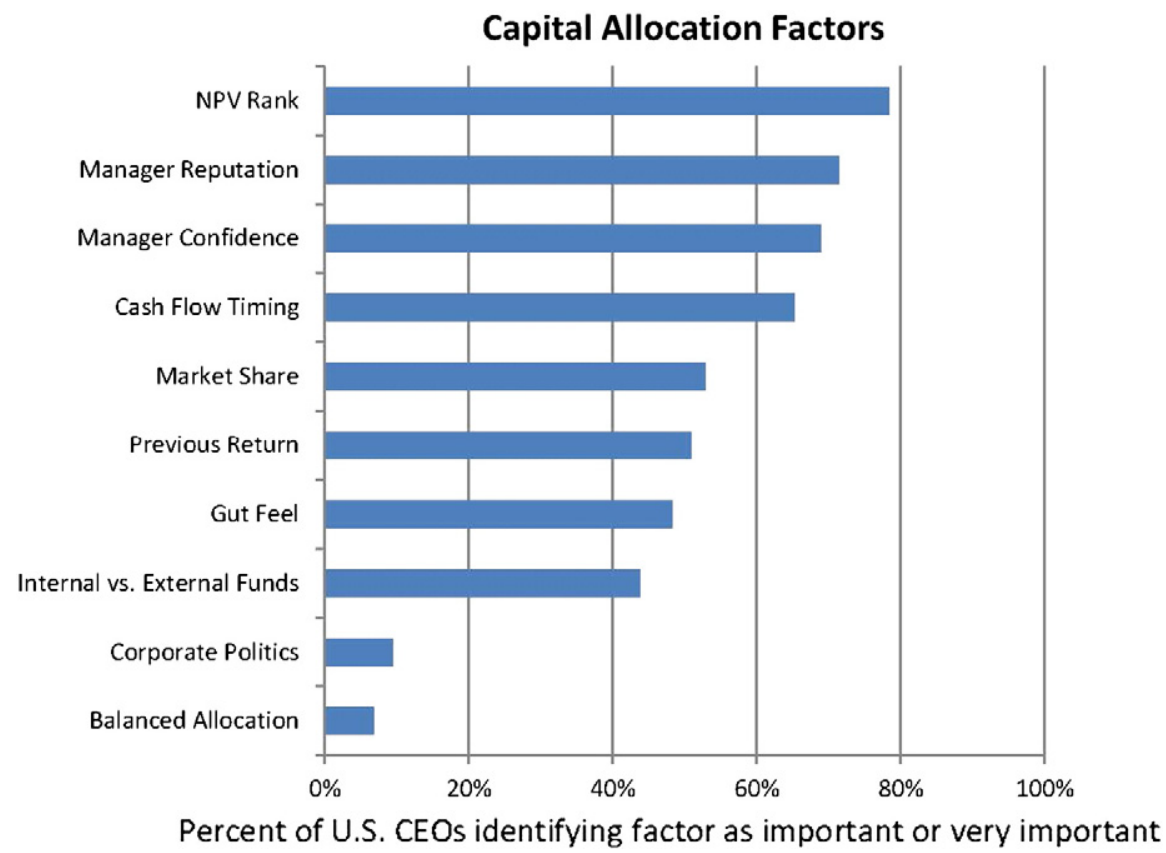

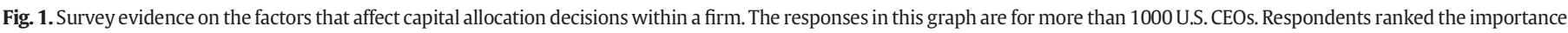
of each deemed to be "important" to a respondent if the ranking was a 4 or 5 .

Adopted from Graham et al. (2012) with permission.

option, Detroit. Their semi-ignorance, arising from the fact that most of them had never heard of Milwaukee allowed them to make better bets. U.S. students who recognized both cities could not use this heuristic; they knew too much. Similarly, mere player name recognition could predict the winners of the 127 Wimbledon Gentleman's matches as well as or better than the Wimbledon experts' seeding and the ATP rankings could (Scheibehenne \& Bröder, 2007; Serwe \& Frings, 2006). A good heuristic can be better than a complex strategy when used in the proper environment. Less can be more. The recognition heuristic is ecologically rational when a correlation exists between recognizing an option and the criteria for judgment. Experimental evidence indicates that people intuitively tend to rely on a heuristic when it is ecologically rational, and less so when it is not (Gigerenzer \& Goldstein, 2011).

The accuracy-effort trade-off is a general principle valid in the Knightian world of known risk. Assuming that it also applies when dealing with uncertainty is a carry over with no methodic justification. Once models of heuristic decision-making are developed, tested, and verified quantitatively, holding the accuracy-effort trade-off as a universal criterion is seen to be unwarranted. The following examples from studies in the business domain clarify this point. Wübben and Wangenheim (2008) compare the accuracy of a one-reason decision-making process, namely, the hiatus heuristic (e.g., "classify a customer who did not purchase from the company for more than nine months as inactive."), against an optimization model (the Pareto/NBD model that integrates more information) and found the same or better performance for the heuristic. The hiatus heuristic, which relies only on one good reason, is much simpler than an optimization technique. In Wübben and Wangenheim's case study, dropping customers from the active list was decided simply based on whether they had passed the threshold of nine months of inactivity; all other available information about the customers was ignored. Ortmann, Gigerenzer, Borges, and Goldstein (2008) compare performance of investment portfolios that benefit from partial ignorance to performances of those portfolios based on customary and sophisticated algorithms. The ignorance-based portfolios performed as well as or better than average of mutual funds, chance portfolios, and some market indices, to name a few. These ignorancebased portfolios included stocks that were highly recognized by laypeople randomly interviewed on the street and were compared among others with portfolios containing stocks recognized by economics and finance graduate students. Here the mechanism at work reveals the beneficial effect of partial ignorance. The recognition heuristic, as discussed earlier, can enable people with partial name recognition to make better selections than the business student would with too much knowledge of the subject matter. Notably, stock portfolios recognized by laypeople outperformed unrecognized stock portfolios across domestic and international markets. The recognition of a stock thus appears to be a good, albeit uncertain proxy for its performance, which reflects a high level of informational efficiency in financial markets. In the studies, as the number of stocks increased, from 10 to 20 and 30 top stocks, the performance of the recognition portfolio decreased, suggesting a condition for the success of this heuristic. Ignorance was more beneficial for international portfolios, suggesting another condition, namely that ignorance is more successful when the environment is less known; a bull market is another proposed condition (Boyd, 2001). The recognition portfolio outperformed the random pick portfolio, which itself notably outperformed experts' picks. In another study, DeMiguel, Garlappi, and Uppal (2009) compare the naïve investment strategy $1 / N$ to the mean-variance scheme and other optimizing algorithms and found naivety to be beneficial under certain conditions.

Marewski, Gaissmaier, and Gigerenzer (2010) observe that "acting fast and predicting accurately illustrate benchmarks that organisms must live up to in order to survive... [H]euristics need to be simple in order to meet these benchmarks, particularly in a world that is so fundamentally uncertain." In a related study, Marewski and Schooler (2011) define three stages, no-knowledge, tartle (barely knowing, not enough to specify), and knowledge, and then compared heuristics based on the simplest of capacities, such as the fluency heuristic, which is based on name recognition, to knowledge-based algorithms in terms of performance. Carefully combining degrees of knowledge, complexity of process rules, and ecological factors such as availability of time, they generated quantitative models of memory that match the best performance of a certain algorithm. Their results specify conditions under which a particular capacity or algorithm would perform most successfully, therefore providing a new aspect of perceiving how effortless choices can be made in complex environments. This mapping from functions of memory to selection of strategies is referred to as the cognitive niche. 
A general overview in Table 2 lists twelve heuristics and some counterintuitive results, as well as citing some studies for each case.

\subsection{Simple strategies match complex situations}

The study of ecological rationality is about pinning down the environmental conditions under which a heuristic performs more accurately and demands less effort than other strategies do. The key element is the distinction between environments of uncertainty and of risk, the former being a better characterization of many interesting choice situations. One way in which heuristics can be categorized is based on the amount of knowledge or information they require in relation to the environment in which they can be successfully used. For example, the fluency heuristic ("choose the alternative that you recognize fastest"; see Table 2) works when information is not abundant and retrieval time is appreciably different for options that cannot be distinguished based on mere recognition. Another example is take-the-best, which ranks the cues by validity and chooses the alternative that has the higher cue value (for the first cue that discriminates between the alternatives), ignoring all other cues. The crucial environmental factors for the ecological rationality of take-the-best include cues that have unequal validities and are redundant, that is, highly intercorrelated (for details see Gigerenzer \& Brighton, 2009). Whereas take-the-best simplifies by ignoring cues as well as dependencies between cues when ranking them, tallying simplifies by giving all cues equal weights. Marewski et al. (2010) report that tallying and its variants, such as $1 / N$, are successful heuristics in a wide range of decision situations, from capital allocation to avalanche forecasting. The rationale is this: Do not try to estimate weights in prediction under uncertainty, in order to avoid estimation error in situations where samples are small or the future is uncertain.

The effective use of a strategy model, is a function of the structure of the environment and the goal of the decision maker. As mentioned, there is no universally best strategy that can be applied across situations. The last paper in this volume (Mousavi \& Kheirandish), which focuses on ecological rationality, starts with the observed probabilitymatching behavior of rodents in the famous T-Maze experiment. In similar settings in natural environments, probability matchers-be they rodents or humans-no longer appear to behave irrationally but are actually better at finding patterns in sequences than in the lab. Moreover, exploratory behavior that looks like probability matching is indispensable for detecting changes in the environment (Gaissmaier, Schooler, \& Rieskamp, 2006). Recall that survival in the wild relies on the reliability of prediction of changes in the environment, where misses are more dangerous than false alarms. In sum, there are beneficial degrees of memory, ignorance, and knowledge beyond which the outcome can worsen. Less can be more under specifiable conditions.

How can a simple heuristic be more accurate than a complex, "rational" model? The accuracy-effort trade-off explanation for heuristics denies the possibility. This assumption is correct in a world of certainty or risks, but not under uncertainty. To better explain this fact, Brighton and Gigerenzer (2012) extend the bias-variance dilemma from machinelearning literature to the study of heuristic models. Every intelligent system makes errors based on three sources: bias, variance, and noise (e.g., measurement error). Psychological studies have been traditionally focused on bias, which is measured by the difference between the average judgment and the true state. An unbiased mind is a mind that can learn everything, including the true state, provided that the sample size is large enough. A biased mind cannot learn everything and thus is less sensitive to errors due to small and faulty samples of observation (the kind of error called "variance"). An intelligent mind relies on heuristic strategies that strike a balance between reducing error due to bias and due to oversensitivity to the specifics of the samples encountered (variance). This balance depends on features of the environment, such as small vs. large samples.

Thus, an intelligent mind needs some beneficial degree of bias, that is, to ignore part of the available information, but also a degree of flexibility, or variance, that allows for a beneficial degree of learning. The combination of these two characteristics makes it possible to achieve low total error and higher accurate predictions under uncertainty. $1 / \mathrm{N}$ is an extreme case in point. It is completely biased but has no error due to variance; it does not attempt to estimate parameters and thus ignores all information in the samples available. Take-the-best (TTB) has only one learning stage, which is learning the order of cues. To do so, TTB ignores all inter-cue dependencies (once again, to reduce variance) and treats them as if they were independent. The conditions under

Table 2

Twelve well-studied heuristics with evidence of use in the adaptive toolbox of humans. Adopted with modification from Table 1-1, pp. 9-10 in Todd et al. (2012).

\begin{tabular}{|c|c|c|}
\hline Heuristic & Description & Counterintuitive results \\
\hline $\begin{array}{l}\text { Recognition heuristic } \\
\text { (Goldstein \& Gigerenzer, 2002) }\end{array}$ & $\begin{array}{l}\text { If one of two alternatives is recognized, infer that it has the higher } \\
\text { value on the criterion. }\end{array}$ & Less-is-more effect \\
\hline $\begin{array}{l}\text { Fluency heuristic } \\
\text { (Schooler \& Hertwig, 2005) }\end{array}$ & $\begin{array}{l}\text { If both alternatives are recognized but one is recognized faster, infer } \\
\text { that it has the higher value on the criterion. }\end{array}$ & Less-is-more effect \\
\hline $\begin{array}{l}\text { Take-the-best } \\
\quad \text { (Gigerenzer \& Goldstein, 1996) }\end{array}$ & $\begin{array}{l}\text { To infer which of two alternatives has the higher value, (a) search } \\
\text { through cues in order of validity; (b) stop search as soon as a cue } \\
\text { discriminates; (c) choose the alternative this cue favors. }\end{array}$ & $\begin{array}{l}\text { Often predicts more accurately than multiple regression, neural } \\
\text { networks, exemplar models, and decision-tree algorithms }\end{array}$ \\
\hline $\begin{array}{l}\text { Tallying } \\
\quad \text { (Dawes, 1979) }\end{array}$ & $\begin{array}{l}\text { To estimate a criterion, do not estimate weights but simply count } \\
\text { the number of positive cues. }\end{array}$ & Often predicts as accurately as or better than multiple regression \\
\hline $\begin{array}{l}\text { Satisficing } \\
\quad \text { (Simon, 1955) }\end{array}$ & $\begin{array}{l}\text { Search through alternatives and choose the first one that exceeds } \\
\text { your aspiration level. }\end{array}$ & $\begin{array}{l}\text { Aspiration levels can lead to substantially better choices than by chance, } \\
\text { even if they are arbitrary. }\end{array}$ \\
\hline $\begin{array}{l}\text { One-bounce rule } \\
\text { (Hey, 1982) }\end{array}$ & $\begin{array}{l}\text { Continue searching (e.g., for prices) as long as options improve; at } \\
\text { the first downturn, stop search and take the previous best option. }\end{array}$ & $\begin{array}{l}\text { Taking search costs into consideration in this rule does not improve } \\
\text { performance. }\end{array}$ \\
\hline $\begin{array}{l}\text { Gaze heuristic } \\
\text { (McBeath, Shafer, \& Kaiser, 1995) }\end{array}$ & $\begin{array}{l}\text { To catch a ball that is coming from down from overhead, fix your } \\
\text { gaze on it, start running, and adjust your running speed so that the } \\
\text { angle of gaze remain constant. }\end{array}$ & Balls will be caught while running, possibly on a curved path. \\
\hline $\begin{array}{l}1 / N \text { rule } \\
\quad \text { (DeMiguel et al., 2009) }\end{array}$ & Allocate resources equally to each of $N$ alternatives. & Can outperform optimal asset allocation portfolios \\
\hline $\begin{array}{l}\text { Default heuristic } \\
\quad \text { (Johnson \& Goldstein, 2003) }\end{array}$ & If there is a default, follow it. & $\begin{array}{l}\text { Explains why advertising has little effect on organ donor registration; } \\
\text { predicts behavior when trait and preference theories fail }\end{array}$ \\
\hline $\begin{array}{l}\text { Tit-for-tat } \\
\quad \text { (Axelrod, 1984) }\end{array}$ & Cooperate first and then imitate your partner's last behavior. & $\begin{array}{l}\text { Can lead to a higher payoff than "rational" strategies (e.g., by backward } \\
\text { induction) }\end{array}$ \\
\hline $\begin{array}{l}\text { Imitate the majority } \\
\text { (Boyd \& Richardson, 2005) }\end{array}$ & $\begin{array}{l}\text { Determine the behavior followed by the majority of people in your } \\
\text { group and imitate it. }\end{array}$ & A driving force in bonding, group identification, and moral behavior \\
\hline $\begin{array}{l}\text { Imitate the successful } \\
\text { (Boyd \& Richardson, 2005) }\end{array}$ & $\begin{array}{l}\text { Determine the most successful person and imitate his or her } \\
\text { behavior. }\end{array}$ & A driving force in cultural evolution \\
\hline
\end{tabular}


which a heuristic strategy is successful can hence be understood based on how much bias and variance is involved. Strategies with a beneficial level of bias-variance are those that are more robust and therefore more successful in prediction.

\subsection{The mind as an adaptive toolbox}

The human mind can be viewed as an adaptive toolbox. This toolbox consists of learned and evolved capacities such as the ability to memorize, recognition memory and recall memory, keeping track of movements, and social abilities such as imitation. These core capacities can be acquired through personal experience, expert training, or evolutionary learning. Heuristics and their building blocks exploit these capacities to make fast judgments. An example is the tit-for-tat heuristic with two building blocks: cooperate first, and then imitate the other person. Implementing this imitation strategy requires certain machinery in the mind. Humans have the capacity to imitate with high precision from an early age and can use tit-for-tat almost effortlessly, whereas the question whether animals use tit-for-tat is still under debate. Notably, this vision of behavior is different from trait psychology, wherein traits, attitudes, or preferences map onto a set of behaviors. The adaptive toolbox view considers behavior as contingent on the heuristic and the environment to which it adapts. This view can easily explain some apparent inconsistencies in behavior by exploring the heuristic in use. For example, teenagers tend to imitate their peers. This can lead to morally reprehensive or morally admirable behavior, depending on the structure of the peer environment.

Another important aspect of information processing concerns modes of communication that shape the absorption of information, leading to different behavior. Mousavi and Gigerenzer (2011) discuss in detail how two representational forms of the same logically equivalent pieces of information can trigger different heuristics, each leading to a different action. This research provides a new look at so-called cognitive biases, which turn out to be the product of an interaction between certain presentation formats and the mind, not a feature of the mind itself. As a consequence, one can teach physicians and patients how to present information so that they understand how to make inferences such as Bayesian inferences (Gigerenzer, Gaissmaier, Kurz-Milcke, Schwartz, \& Woloshin, 2007).

\subsection{How good is a heuristic?}

Heuristics can be evaluated on two grounds. The descriptive evaluation asks whether heuristics provide a good model for people's decisionmaking. The normative evaluation concerns whether heuristics perform well for a given task. Most psychological studies of heuristics are about the first question: What is in the adaptive toolbox? The study of the adaptive toolbox reveals which models of heuristics best describe how people made decisions in given situations. The second question pertains to the ecological rationality of a heuristic: In what environment will a given heuristic succeed or fail? As a study program, ecological rationality has devised three methods: (1) Mathematical proof. For instance, if the weights of cues (predictors) are non-compensatory, no linear model can make better inferences than the take-the-best heuristic, which relies on only one cue (Martignon \& Hoffrage, 2002). This analytical research typically uses worlds of certainty, that is, where all information is known. (2) Simulations with computer-generated data. This method facilitates comparing the performance of different strategies on large data sets. Here, the world of certainty is changed into one of risk, for instance, by adding error to a linear data generation model (e.g., Hogarth \& Karelaia, 2007). (3) Predictions with real and computer-generated data. Here we deal with various degrees of uncertainty, where predictions need to be made out-of-sample or out-of population (e.g., Gigerenzer \& Brighton, 2009).

The study of models of decision-making, descriptively (what heuristics do people use?) and normatively (in which world does a given heuristic succeed?), is based on a set of methodological principles. This methodology dictates a specific order of exploration: develop a testable model, predict the results based on this model, and only then gather data. Formal models of heuristic do not merely describe observed phenomenon after the fact, but provide a platform for competitive testing to identify and develop superior theories. Evaluation of a model is only meaningful in comparison with other models, not merely by fitting or describing an observed phenomenon. Comparative evaluations can identify better models of behavior in a given context, including the contexts in which non-heuristic (e.g., optimization) models prove superior. This methodology focuses on the comparison between competing models rather than on null hypothesis testing based on one model. Cross-validation techniques are used to go beyond data fitting and to evaluate models based on prediction accuracy. A model without free parameters, such as $1 / N$, will show the same accuracy in fitting and prediction, whereas multiple regression models and other models with multiple free parameters can fit data well after the fact but often show considerably less accuracy in prediction, depending on the sample size and other features. Predictive accuracy is of utmost importance because humans (and animals) have to be good at predicting to survive, whereas fitting equals hindsight and is not necessarily of survival value or of value in making good decisions (or judgments) under uncertainty.

\section{A bird's-eye view of effective business decision-making}

In the domain of business decision-making, plenty of information is often available. However, many decisions are finally made based on gut feelings. Managers of large international corporations admit that about half of their professional decisions are gut decisions, based on their experience after having considered all the data available (Gigerenzer, 2014). Yet few would admit that publicly but instead ask employees or, as a more expensive option, engage a consulting firm to deliver reasons after the fact. One reason for this smokescreen is the assumption that all decisions need to be justified by numbers, as if all risks could be calculated. In contrast, gut feelings are typically based on heuristics, that is, on what Knight called an intuitive estimate that does not fit into the architecture of calculations.

As mentioned before, Knight introduced three forms of probability: a priori probability, statistical probability, and estimate. Knight's conception of probability predates Savage's notion and so must be read with a fresh mind. A priori and statistical probability correspond to risk, whereas the use of what Knight calls "estimates" occurs when dealing with uncertainty. Knight argued that the last category of situations is not meaningfully reducible to statistical calculations and he considered the associated uncertainty as immeasurable. His humorous characterization of the mainstream practice of using probability measures to model all uncertain decision situations is most illustrative: "If you cannot measure it, measure it anyway!" (Bernstein, 1996). One main point in the business world is that entrepreneurs can generate profit in the markets, à la Knight, precisely because they intelligently deal with immeasurable, irreducible uncertainty. We argue that the study of heuristics provides a descriptive and normative framework to model how entrepreneurs and others deal-and should deal-with uncertainty.

The study of the ecological rationality of simple choice strategies such as the recognition heuristic and $1 / N$ heuristic does not simply claim that simplicity, be it ignorance or naivety, is always better. Rather, it explores the environmental structures in which such simple heuristics would fare well. For example, the recognition heuristic fits a task environment when recognition correlates with the criterion and the agent has partial knowledge. For the agent who is highly knowledgeable or does not know anything about the task, recognition is not a winning strategy. Similarly, naivety can be rewarding in highly complex and rapidly changing environments such as the stock market. A heuristic strategy is ecologically rational under certain conditions. For example, the naïve portfolio selection strategy, $1 / N$, appears to be ecologically 
rational if (1) $N$ is large, (2) sample size is small, and (3) predictive uncertainty is high. A testable heuristic model can provide, in turn, normative recommendations for successful action.

The study of the ecological rationality of heuristics can inform managerial decision-making research. Katsikopoulos and Gigerenzer (2013) point out that behavioral operations management research has focused on only one view about heuristics, which associates heuristics with biases and therefore considers them mainly as liabilities. Instead, Katsikopoulos and Gigerenzer propose a research agenda expanding on the ecological rationality of heuristics that complements the existing body of work by providing a framework for when and where heuristics are liabilities in management and when they are assets. A main point is to realize the importance of the descriptive adequacy of models, which as discussed is high for heuristic models across domains.

In most business situations knowledge is much less than perfect and uncertainty prevails over risk. Heuristic strategies that are successfully used in business decision-making exploit the structure of information in the environment, rely on simplicity to overcome the complexity of situation, and are indispensable when faced with irreducible uncertainty. One central observation is that less can be more. That is, less information, calculation or time, can be beneficial under particular circumstances to achieving a given task.

In this volume, several instances of business decision-making under uncertainty are shown to have organically produced rules of thumb (heuristics) that successfully perform in complex market situations. Ecological rationality, as a research program, aims at teasing out the building blocks of such successful heuristic strategies. These building blocks that can be refined and tailored to new situations.

The papers in this volume illustrate how the program of ecological rationality can be made useful in the business world. Rusetski describes the successful and continuing use of intuition by managers in the process of pricing. McGillivray analyzes rule-based judgment processes in fast-and-frugal crisis management. Hu and Wang identify heuristics for making trust-based choices in HR management. Monti, Pelligra, Martignon, and Berg provide evidence for an advice-taking heuristic that influences trust. Hauser presents a state-of-the-art review of the theory and measurement of consumers' heuristic consideration-set rules, with managerial examples. Berg discusses implications of satisficing and imitation heuristics to entrepreneurial choice of location. Nikolaeva investigates imitate the successful and imitate the majority, two heuristics based on past experience and social learning in organizations in relation to innovation. Shefrin and Nicols investigate heuristics that can improve customers' spending and borrowing behavior by identifying different styles of credit card usage. Azar develops a model of information search and derives the conditions under which the default heuristic arises as the preferred strategy. Olsson discusses methodological issues concerning the measurement and nature of overconfidencea phenomenon that overwhelms managerial decision-making literature. Fific and Gigerenzer show that in the case of job interviews the "more is better" principle does not apply-providing evidence for the less-ismore phenomenon. In the closing article, Mousavi and Kheirandish juxtapose the conception of ecological rationality in two prominent research traditions based on interviews conducted with Vernon Smith and Gerd Gigerenzer.

The study of heuristics as effective strategies in business and other fields is only at the beginning of its exploration. This flourishing path leads to a science of heuristics, which systematically classifies their building blocks as well as the relations between combinations of these building blocks and the structure of environments in which they solve problems effectively. Studying heuristics is a fruitful scientific strategy for developing reliable knowledge in dealing with uncertainty instead of trying to reduce all uncertainty to risk. The old dream of the philosopher Leibnitz of being able to calculate the answer to all questions is a heavenly one, but on earth we live in the twilight of uncertainty. Compared to this dream, here is a certain realism rooted in Knight's (1921, p. 311) plea for modesty: "The results of human activity cannot be anticipated and then only in so far as even a probability calculation in regard to them is impossible and meaningless."

\section{References}

Axelrod, R. (1984). The evolution of cooperation. New York: Basic Books.

Bernstein, P. L. (1996). Against the gods: The remarkable story of risk. John Wiley \& Sons, Inc. (1998).

Bewley, T. F. (2002). Knightian decision theory. Part I. Decision in Economics and Finance, $25,79-110$

Boyd, M. (2001). On ignorance, intuition and investing: A bear market test of the recognition heuristic. Journal of Psychology and Financial Markets, 2, 150-156.

Boyd, R., \& Richardson, P. J. (2005). The origin and evolution of cultures. New York: Oxford University Press.

Brighton, H. J., \& Gigerenzer, G. (2012). Homo heuristicus and the bias-variance dilemma. In J. Schulkin (Ed.), Action, perception and the brain: Adaptation and cephalic expression (pp. 68-91). Basingstoke: Palgrave Macmillan.

Daston, L. (1988). Classical probability in the enlightenment. Princeton: Princeton University Press.

Dawes, R. M. (1979). The robust beauty of improper linear models in decision making. American Psychologist, 34, 571-582.

DeMiguel, V., Garlappi, L., \& Uppal, R. (2009). Optimal versus naïve diversification: How inefficient is the $1 / \mathrm{N}$ portfolio strategy? Review of Financial Studies, 22, 1915-1953.

Gaissmaier, W., Schooler, L. J., \& Rieskamp, J. (2006). Simple predictions fueled by capacity limitations: When are they successful? Journal of Experimental Psychology Learning Memory and Cognition, 32, 966-982.

Gigerenzer, G. (2007). Gut feelings: The intelligence of the unconscious. New York: Viking Press. Gigerenzer, G. (2014). Risk savvy: How to make good decisions. New York: Viking.

Gigerenzer, G., \& Brighton, H. (2009). Homo heuristicus: Why biased minds make better inferences. Topics in Cognitive Science, 1, 107-143.

Gigerenzer, G., Gaissmaier, W., Kurz-Milcke, E., Schwartz, L. M., \& Woloshin, S. (2007). Helping doctors and patients to make sense of health statistics. Psychological Science in the Public Interest, 8, 53-96.

Gigerenzer, G., \& Goldstein, D. G. (1996). Mind as computer: Birth of a metaphor. Creativity Research Journal, 9, 131-144.

Gigerenzer, G., \& Goldstein, D. G. (2011). The recognition heuristic: A decade of research. Judgment and Decision Making, 6, 100-121.

Gigerenzer, G., Hertwig, R., \& Pachur, T. (Eds.). (2011). Heuristics: The foundations of adaptive behavior. New York: Oxford University Press.

Gigerenzer, G., \& Sturm, T. (2012). How (far) can rationality be naturalized? Synthese, 187, 243-268.

Gigerenzer, G., Todd, P. M., \& the ABC Research Group (1999). Simple heuristics that make us smart. New York: Oxford University Press.

Goldstein, D. G., \& Gigerenzer, G. (2002). Models of ecological rationality: The recognition heuristic. Psychological Review, 109, 75-90.

Graham, J. R., Harvey, C. R. \& Puri, M. (2012). Capital allocation and delegation of decision-making authority within firms. Working paper. Duke University (Available: http://ssrn.com/abstract=1527098).

Haldane, A. G. (2012). The Dog and the Frisbee. Federal Reserve Bank of Kansas City's 36th economic policy symposium, "The changing policy landscape" Jackson Hole, Wyoming USA.

Hey, J. D. (1982). Search for rules for search. Journal of Economic Behavior and Organization, 3, 65-81

Hogarth, R. M., \& Karelaia, N. (2007). Heuristic and linear models of judgment: Matching rules and environments. Psychological Review, 114(3), 733-758 (7)

Johnson, E. J., \& Goldstein, D. G. (2003). Do defaults save lives? Science, 302, 1338-1339.

Kahneman, D., \& Frederick, S. (2002). Representativeness revisited: Attribute substitution in intuitive judgment. In T. Gilovich, D. Griffin, \& D. Kahneman (Eds.), Heuristics and Biases: The Psychology of Intuitive Judgment (pp. 49-81). New York: Cambridge Univ. Press.

Katsikopoulos, K. V., \& Gigerenzer, G. (2013). Behavioral operations management: A blind spot and a research program. Journal of Supply Chain Management, 49, 3-7.

Knight, F. H. (1921). Risk, uncertainty and profit. Dover 2006 unabridged republication of the edition published by. Boston and New York: Houghton Mifflin Company.

Marewski, J. N., Gaissmaier, W. \& Gigerenzer, G. (2010). We favor formal models of heuristics rather than lists of loose dichotomies: A reply to Evans and Over. Cognitive Processing, 11, 177-179.

Marewski, J. N., \& Schooler, L. J. (2011). Cognitive niches: An ecological model of strategy selection. Psychological Review, 118(3), 393-437 (2011).

Martignon, L., \& Hoffrage, U. (2002). Fast, frugal, and fit: Simple heuristics for paired comparison. Theory and Decision, 52(1), 29-71.

McBeath, M. K., Shafer, D. M., \& Kaiser, M. K. (1995). How baseball outfielders determine where to run to catch fly balls. Science, 268, 569-573.

Mousavi, S., \& Gigerenzer, G. (2011). Revisiting the "error" in studies of cognitive errors. In D. A. Hofmann, \& M. Frese (Eds.), Errors In Organizations (pp. 97-112). New York: Taylor \& Francis.

Ortmann, A., Gigerenzer, G., Borges, B., \& Goldstein, D. G. (2008). The recognition heuristic: A fast and frugal way to investment choice? In C. R. Plott, \& V. L. Smith (Eds.), Handbook of experimental economics results 1 (pp. 993-1003). Amsterdam: NorthHolland (Handbooks in Economics No. 28).

Savage, L. J. (1954). The foundations of statistics. New York: Dover: John Wiley and Sons (1972 edition of the original 1954).

Scheibehenne, B., \& Bröder, A. (2007). Predicting Wimbledon 2005 tennis results by mere player name recognition. International Journal of Forecasting, 23, 415-426.

Schooler, L. J., \& Hertwig, R. (2005). How forgetting aids heuristic inference. Psychological Review, 112, 610-628. 
Serwe, S., \& Frings, C. (2006). Who will win Wimbledon? The recognition heuristic in predicting sports events. Journal of Behavioral Decision Making, 19, $321-332$.

Shah, A. K., \& Oppenheimer, D. M. (2008). Heuristics made easy: an effort-reduction framework. Psychological Bulletin, 137, 207-222.

Shapira, Z. (1994). Risk taking: A managerial perspective. New York: The Russell Sage Foundation.

Shefrin, H. (2013). Assessing the contribution of Hyman Minsky's perspective to our understanding of economic instability. Working paper. Santa Clara University (Available: http://papers.ssrn.com/sol3/papers.cfm?abstract_id=2311045).
Simon, H. A. (1955). A behavioral model of rational choice. Quarterly Journal of Economics, 69, 99-118.

Todd, P. M., Gigerenzer, G., \& the ABC Research group (2012). Ecological rationality: Intelligence in the world. New York: Oxford University Press.

von Neumann, J., \& Morgenstern, O. (1944). Theory of games and economic behavior. Princeton University Press.

Wall Street Journal: Speech of the Year 2012. Available: http://online.wsj.com/news articles/SB10000872396390444273704577637792879194380

Wübben, M., \& Wangenheim, F. v (2008). Instant Customer Base Analysis: Managerial Heuristics Often “Get It Right”. Journal of Marketing, 72, 82-93 (May 2008). 